\title{
Characteristics of the semen of three endangered species of gazelles (Gazella dama mhorr, G. dorcas neglecta and G. cuvieri)
}

\author{
J. Cassinello ${ }^{1}$, T. Abaigar ${ }^{2}$, M. Gomendio ${ }^{1}$ and E. R. S. Roldan ${ }^{3 *}$ \\ ${ }^{1}$ Departamento de Ecología Evolutiva, Museo Nacional de Ciencias Naturales, CSIC, clJosé Gutiérrez \\ Abascal 2, 28006-Madrid, Spain; ${ }^{2}$ Estación Experimental de Zonas Aridas, CSIC, c/Gral. Segura 1 , \\ 04001-Almería, Spain; and ${ }^{3}$ Instituto de Bioquímica (CSIC-LCM), Facultad de Farmacia, Universidad \\ Complutense, 28040-Madrid, Spain
}

\begin{abstract}
As part of a captive breeding programme for three species of endangered gazelles (Gazella dama mhorr, $G$. dorcas neglecta and $G$. cuvieri) the semen parameters for each species were characterized. The volume of ejaculated semen varied widely within species ( $G$. dama:

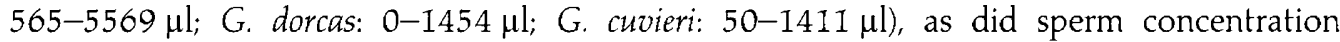
(G. dama: $14-1629 \times 10^{6} \mathrm{ml}^{-1}$; G. dorcas: $197-2836 \times 10^{6} \mathrm{ml}^{-1}$; G. cuvieri: $228-927 \times$ $\left.10^{6} \mathrm{ml}^{-1}\right)$. Sperm motility and viability were high in the three species. G. dama had a significantly lower proportion of normal spermatozoa, with a significantly higher proportion having abnormal heads and midpieces and more spermatozoa with cytoplasmic droplets. In addition, $G$. dama tended to have a lower proportion of spermatozoa with normal acrosomes. Sperm heads in G. dama and G. cuvieri were pear-shaped, whereas they were oval in $G$. dorcas. Spermatozoa from $G$. cuvieri were the longest. These data were also analysed in the context of three hypotheses that could explain inter-species differences in semen characteristics. Differences in testes size were due largely to differences in body size between species. However, no semen characteristic could be explained by allometric relationships. The three gazelle species differed in the intensity of sperm competition (as measured by relative testes mass), a factor that could explain differences in the proportion of normal spermatozoa. Finally, although the three species have reached different levels of inbreeding, this factor did not explain differences in semen characteristics in the population.
\end{abstract}

\section{Introduction}

For an increasing number of species, captive breeding represents their best chance for avoiding extinction. The World Conservation Union (IUCN) has recognized the potential role that captive breeding may play in conservation efforts and has recommended that vertebrate taxa numbering less than 1000 individuals in the wild should be considered for captive breeding (IUCN, 1987). Since 1971 the "Estación Experimental de Zonas Aridas" (EEZA) has developed captive breeding programmes for three endangered gazelle species: Gazella dama mhorr, G. dorcas neglecta and G. cuvieri. These three species have reproduced successfully in captivity, allowing the translocation of animals to several zoos in Europe and the USA. The history and reproductive aspects of the populations of these three species have been described by Olmedo et al. (1985), Alados ef al. (1988), Alados and Escos (1991) and Cano (1991).

The general distribution of Gazella dama mhorr includes Southwest Morocco and Western Sahara. This species is categorized in the IUCN Red List of Threatened Animals (IUCN, 1996) as 'Endangered', and no wild animals have been

\footnotetext{
${ }^{*}$ Correspondence.
}

Revised manuscript received 7 August 1997. observed since 1968. The first individuals were brought to the EEZA in 1971, and the founder population consisted of three males and nine females. Gazella dorcas neglecta inhabits semidesert planes and desert areas of Western Sahara (see Abaigar, 1993). The species as a whole is categorized as 'Lower risk: near threatened' (IUCN, 1996) but the Red List does not specify the status of $G$. dorcas neglecta, which is thought to be endangered. Wild populations are believed to have suffered a marked decline due to poaching. Individuals belonging to this species arrived at the EEZA in different groups between 1970 and 1975. New individuals were incorporated in 1993 and 1994. On the whole, the founder population consisted of 11 males and 13 females. The general distribution of Gazella cuvieri includes the mountain regions of Morocco, Algeria and Tunisia (see Escos, 1992). Extensive habitat destruction and hunting have reduced the wild population to small scattered groups inhabiting inaccessible areas. The species is categorized (IUCN, 1996) as 'Endangered'. In 1975, one male and two females were brought to the EEZA, and in 1986, a new male was incorporated into the population. Thus, the founder population consisted of two males and two females.

The ultimate goal of captive breeding programmes dealing with endangered species should be to implement management policies that will maintain the potential of recreating a 
self-sustaining wild population (Ebenhard, 1995). Among the most important threats faced by captive populations are the loss of genetic variability and inbreeding. These factors imply serious risks owing to the small founder populations for the gazelles kept at the EEZA. Detailed records kept at the EEZA, since the founder populations were first established, have allowed the calculation of inbreeding coefficients for all individuals. On the basis of this information, deleterious effects of inbreeding have been found on some components of the reproductive success of the three species of gazelle (Alados and Escos, 1991). In this context, artificial insemination and semen preservation have been identified as powerful tools in the breeding programmes of gazelles (Holt et al, 1996a), since this would allow the storage of semen from genetically valuable animals, extend generation times, circumvent husbandry or medical factors that may prevent certain animals from breeding, and transfer semen between subpopulations that may become geographically or biologically isolated (Wildt, 1992; Holt et al., 1996b).

Holt et al. (1996a) showed the feasibility of artificial insemination in G. dama mhorr, but have also highlighted difficulties encountered with available protocols for semen cryopreservation. So far, no studies have been carried out on semen preservation in G. dorcas or G. cuvieri, although there are previous efforts to characterize seasonal variations in ejaculate quality in G. dorcas (Howard et al., 1983). Furthermore, semen preservation in related antelopes has received limited attention (for example, Boever et al., 1980; Holt et al., 1988; Garland, 1989). Therefore, better protocols of semen handling and cryopreservation are required for these species to achieve the high percentages of sperm survival and fertility obtained in other species of wild or semi-domesticated ungulates (for example, Jabbour et al., 1993; Monfort et al., 1993). In addition, it is important to understand which factors influence sperm production and quality in our captive breeding programme and whether such variation in ejaculate quality may be related to genotypic effects (that is, inbreeding), or could be the result of evolutionary forces such as sperm competition.

This study was undertaken to (a) characterize the ejaculate quality of the three species of gazelle (G. dama mhorr, G. dorcas neglecta, G. cuvieri) that are part of our captive breeding programme, (b) analyse the morphology and dimensions of spermatozoa from the three species, (c) examine whether variations in ejaculate parameters are related to bodyweight or testes mass, (d) investigate whether differences in ejaculate quality could be related to sperm competition in any of these species, and (e) test whether ejaculate quality is related to the level of inbreeding of the populations kept at the EEZA.

\section{Materials and Methods}

\section{Animals}

Adult gazelles of the three species used in this study were maintained and managed by the EEZA. The research station is located at $36^{\circ} 50^{\prime} 10^{\prime \prime}$ north, and $2^{\circ} 27^{\prime} 48^{\prime \prime}$ west, at $100 \mathrm{~m}$ above sea level. Ten $G$. dama mhorr males (age $>3$ years, weight $>55 \mathrm{~kg}$ ), eight $G$. dorcas neglecta males (age $>2.5$ years, weight $>14 \mathrm{~kg}$ ) and eight G. cuvieri males (age $>5$ years, weight $>32 \mathrm{~kg}$ ) were used. All the males were kept either as isolated animals or in groups of three to five males.

\section{Semen collection}

Semen was collected between September and November 1996 from healthy and reproductively mature males. This time of the year was chosen because, in G. cuvieri, there is a peak in mating activities (Olmedo et al., 1985); the other two species do not follow a seasonal pattern. In a first series of experiments, ejaculates were collected from $G$. dama individuals and used to compare several methods of semen evaluation. In a second series, semen was collected from G. dama, G. dorcas and G. cuvieri individuals and the ejaculate was characterized macro- and microscopically.

Semen collection was performed under surgical anaesthesia (Holt et al., 1996a), using a combination of intramuscular xylazine $\left(0.2 \mathrm{mg} \mathrm{kg}^{-1}\right.$ bodyweight) (Bayer, Barcelona) and intravenous ketamine chlorohydrate ( $15 \mathrm{mg} \mathrm{kg}^{-1}$ bodyweight) (Rhône Merieux, Lyon).

Bodyweight and testicular dimensions were obtained during anaesthesia just before electroejaculation. Testes mass was calculated as described by Harcourt et al. (1995) using the maximum length and width of each testis.

Semen was collected by electroejaculation as described by Holt et al. (1988, 1996a). Nylon rectal probes, fitted with four surface-mounted strip electrodes (probe diameter: $2.5 \mathrm{~cm}$ for G. dama and G. cuvieri; $1.95 \mathrm{~cm}$ for G. dorcas; electrode length: $6.5 \mathrm{~cm}$ for G. dama and G. cuvieri; $6 \mathrm{~cm}$ for $G$. dorcas), were inserted into the rectum and voltage applied. Pulses of $5-9 \mathrm{~V}(50 \mathrm{~Hz})$ lasting $4 \mathrm{~s}$ with intermittent breaks of $4 \mathrm{~s}$ were used for G. dama, whereas for G. dorcas and G. cuvieri, pulses of $1-5 \mathrm{~V}(50 \mathrm{~Hz})$ lasting $4 \mathrm{~s}$ with intervals of $4 \mathrm{~s}$ were applied. Semen samples were usually obtained after five pulses.

On completion of semen collection, the effects of anaesthesia were reversed by intravenous administration of the antidote, yohimbine chlorohydrate $\left(0.025 \mathrm{mg} \mathrm{kg}^{-1}\right.$ bodyweight) (generously supplied by C. Gimjaune, Hospital 14, Barcelona).

\section{Semen evaluation}

Sperm volume, concentration, and subjective scores of motility (wave motion, individual and progressive motility) were determined within $40-60$ min of collection. Also within this interval, aliquants were diluted in a modified Tyrode's medium (see below) and used to assess individual sperm motility, sperm morphology, and acrosome integrity.

The volume was measured aspirating semen with a micropipette. Concentration was estimated using a haemocytometer. Semen was diluted (1:50) with a modified Tyrode's medium with the following composition: $120 \mathrm{mmol} \mathrm{NaCl} 1^{-1}$, $3.1 \mathrm{mmol} \mathrm{KCl} \mathrm{l}{ }^{-1}, 2 \mathrm{mmol} \mathrm{CaCl} 1^{-1}, 0.4 \mathrm{mmol} \mathrm{MgSO}_{4} \mathrm{l}^{-1}$,

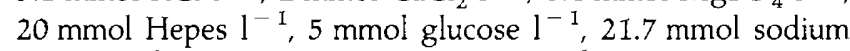
lactate $\mathrm{I}^{-1}, 1 \mathrm{mmol}$ sodium pyruvate $\mathrm{l}^{-1}, 20 \mu \mathrm{g}$ phenol red $\mathrm{ml}^{-1}$, and $5 \mathrm{mg}$ bovine serum albumin $\mathrm{ml}^{-1}$. The $\mathrm{pH}$ of the medium was 7.58 (adjusted with $\mathrm{NaOH}$ ).

Motility was assessed by placing $10 \mu \mathrm{l}$ of sperm suspension between a glass slide and a $22 \mathrm{~mm} \times 22 \mathrm{~mm}$ coverslip, prewarmed to $37^{\circ} \mathrm{C}$. The proportion of motile spermatozoa and 
of spermatozoa with progressive motility (among motile ones) in each sample was assessed subjectively. In addition, motility was rated using a scale 0-5 (0: non-motile; 5 : highly motile).

Aliquots of spermatozoa, suspended in modified Tyrode's medium, were also used to assess sperm viability, morphology and acrosomal integrity by means of various fixation and staining procedures.

Viability was assessed by staining aliquots of sperm suspension with eosin-nigrosin. The eosin-nigrosin solution was prepared as described by Tamuli and Watson (1994). Briefly, $10 \mathrm{~g}$ nigrosin (C.I. 50420; Merck, Darmstadt) was dissolved in distilled water by boiling and filtered into a cylinder containing $0.7 \mathrm{~g}$ eosin yellowish (C.I. 45380; Panreac, Barcelona), $7.5 \mathrm{ml} 50 \mathrm{mmol}$ glucose $1^{-1}$ and $7.5 \mathrm{ml}$ tartrate phosphate buffer (TPB) $\left(50 \mathrm{mmol} \mathrm{Na}_{2} \mathrm{PO}_{4} \mathrm{I}^{-1}, 25 \mathrm{mmol}\right.$ $\mathrm{KH}_{2} \mathrm{PO}_{4} \mathrm{l}^{-1}, 77 \mathrm{mmol}$ potassium sodium tartrate $\mathrm{l}^{-1}$ ), and the volume brought to $100 \mathrm{ml}$. The solution was kept at $5^{\circ} \mathrm{C}$. Staining was carried out by mixing an aliquot of sperm suspension with eosin-nigrosin solution (1:3) for $30 \mathrm{~s}$ before preparing a smear and drying on a warm plate at $37^{\circ} \mathrm{C}$. In addition, aliquots of sperm suspension were stained first with eosin-nigrosin, smeared, air-dried, fixed and then stained with Giemsa (Tamuli and Watson, 1994), as indicated below.

For fixation aliquots of sperm suspension were either (a) diluted $(1: 100-1: 200)$ in $0.1 \%$ formaldehyde in $0.9 \%(\mathrm{w} / \mathrm{v})$ $\mathrm{NaCl}, 0.1 \%(\mathrm{w} / \mathrm{v})$ polyethylene glycol compound and $1 \mathrm{mmol}$ EDTA $1^{-1}, \mathrm{pH} 7.0$, or (b) diluted $1: 1$ in $2 \%(\mathrm{w} / \mathrm{v})$ glutaraldehyde in $0.165 \mathrm{~mol}$ cacodylate $/ \mathrm{HCl} 1^{-1}$ buffer $(\mathrm{pH} 7.3)$ (Shams-Borhan and Harrison, 1981). Sperm morphology and acrosomal integrity were assessed from wet preparations made between slides and coverslips, sealed with nail varnish, and observed using phase contrast optics (total magnification $\times 400$ and $\times 1000$ ).

For Giemsa staining, aliquots of sperm suspension were smeared onto glass slides, air dried, fixed in $4 \%$ formaldehyde in TPB, rinsed in slow running water for $10 \mathrm{~min}$, and then with distilled water before immersion in Giemsa stain solution, which consisted of $4.5 \mathrm{ml}$ Giemsa (BDH, Poole, Dorset) stock solution (Watson, 1975), $3 \mathrm{ml}$ TPB and $32.5 \mathrm{ml}$ distilled water, and was prepared fresh before use. Slides were finally rinsed with distilled water and dried in air.

For lectin staining, aliquots of sperm suspension were smeared onto glass slides, air dried, fixed in ethanol and stained for $15 \mathrm{~min}$ with fluorescein isothiocyanate conjugated to the lectin Pisum sativum (FITC-PSA; Sigma, Madrid) (0.1 mg FITC-PSA $\mathrm{ml}^{-1}$ physiological saline).

Sperm morphology was categorized either as normal, or with abnormalities in the head, midpiece or rest of the flagellum. Coiled tails and presence of cytoplasmic droplets were also noted. A modification to the classification originally used by Pursel $e$ al. (1972) was used to determine acrosomal status. Three categories were used: (a) spermatozoon with a normal apical ridge (NAR), (b) spermatozoon with a damaged or modified apical ridge, or damaged acrosomal cap (DAR), and (c) spermatozoon with a missing apical ridge or lost acrosomal cap (MAR). The other two categories of Pursel et al. (1972) were not used. Hence, spermatozoa with particles (NAR') were included in NAR (see Pursel et al., 1972), whereas spermatozoa with loose (almost detached) acrosomal caps (LAC) were regarded as MAR. The same categories were used for spermatozoa stained with FITC-PSA, and they corresponded to the following staining patterns: (a) spermatozoa with acrosomal region brightly stained, or with perimeter of acrosome brightly stained and the remaining acrosomal region stained less intensely (NAR); (b) patchy staining of acrosomal region, with acrosomes partially detached (DAR); and (c) no staining (MAR).

\section{Dimensions of spermatozoa}

Dimensions of spermatozoa were obtained from eosinnigrosin/Giemsa-stained smears. Images were captured using a Nikon Labophot- 2 microscope fitted with a $\times 40$ objective and bright-field illumination, a camera eyepiece $(\times 1)$, and a CCD black and white video camera (Sony SSC-M370CE). Images were taped using a video cassette recorder (Sony SVO-1500P) and were then digitized and analysed using an IBM-compatible computer with Visilog software (Visilog version 4.1.3 Rev 6, Noesis, Vélizy). Twenty-five spermatozoa from each individual ( $n=8$ individuals for G. dama and G. cuvieri and $n=7$ for $G$. dorcas) were measured. Average values of each sperm component (head, midpiece, principal plus terminal piece) were calculated for each male and these were then used to calculate averages for each species.

\section{Statistical analyses}

Unless stated otherwise, 100-200 spermatozoa were counted in each preparation. Results are means \pm SEM. The analysis of variance (ANOVA) has been used for all analyses, and the usual transformations were applied to variables that were not normally distributed (see Zar, 1984).

\section{Results}

\section{Semen evaluation using different Exation and staining methods}

Semen from G. dama was collected by electroejaculation and evaluated soon after collection. Staining with eosin-nigrosin revealed that the proportion of live cells (that is, unstained spermatozoa) was high and not different from the proportion of live cells in samples stained first with eosin-nigrosin and then with Giemsa (data not shown). This result indicates that washing after eosin-nigrosin staining did not lead to leakage of dye (compare with Tamuli and Watson, 1994). Staining with the latter method was reliable and gave preparations of very good quality as described for ram and boar spermatozoa (Tamuli and Watson, 1994), although, on occasions, it was necessary to increase the concentration of Giemsa, or to extend the staining period.

The morphology of spermatozoa was assessed in wet preparations after fixation with formaldehyde or glutaraldehyde, or in smears stained first with eosin-nigrosin and then with Giemsa. A comparison of the proportions of spermatozoa with either normal morphology, or with different types of abnormality (Table I) revealed that the three methods used showed little differences. Formaldehyde appeared to 
Table 1. Assessment of the morphology in fresh semen from Gazella dama mhorr using formaldehyde or glutaraldehyde fixation, or staining with eosin-nigrosin/Giemsa

\begin{tabular}{|c|c|c|c|c|c|c|}
\hline Method & $\begin{array}{c}\text { Percentage of } \\
\text { normal spermatozoa }\end{array}$ & $\begin{array}{c}\text { Percentage } \\
\text { with abnormal } \\
\text { heads }\end{array}$ & $\begin{array}{c}\text { Percentage } \\
\text { with abnormal } \\
\text { midpiece }\end{array}$ & $\begin{array}{c}\text { Percentage } \\
\text { with abnormal } \\
\text { principal/terminal } \\
\text { piece }\end{array}$ & $\begin{array}{l}\text { Percentage } \\
\text { with coiled } \\
\text { tails }\end{array}$ & $\begin{array}{c}\text { Percentage with } \\
\text { cytoplasmic } \\
\text { droplets }\end{array}$ \\
\hline Formaldehyde & $73.0 \pm 4.69$ & $4.2 \pm 0.75$ & $4.0 \pm 0.62$ & $10.0 \pm 2.48$ & $2.5 \pm 1.19$ & $6.0 \pm 2.04$ \\
\hline Glutaraldehyde & $79.7 \pm 7.12$ & $3.0 \pm 1.68$ & $2.2 \pm 1.03$ & $6.2 \pm 2.84$ & $1.2 \pm 0.95$ & $7.0 \pm 1.73$ \\
\hline Eosin-nigrosin/Giemsa & $83.0 \pm 4.43$ & $2.2 \pm 0.75$ & $3.2 \pm 0.95$ & $6.0 \pm 2.27$ & $0.5 \pm 0.29$ & $4.6 \pm 4.17$ \\
\hline
\end{tabular}

Values are means \pm stM. Assessments were made on independent samples ( $n=4$ males).

Table 2. Assessment of acrosome integrity of spermatozoa in fresh semen from Gazella dama mhorr using formaldehyde or glutaraldehyde fixation, or staining with eosin-nigrosin/Giemsa or FITC-PSA*

\begin{tabular}{lccc}
\hline Method & $\begin{array}{c}\text { Percentage } \\
\text { with normal } \\
\text { apical ridge }\end{array}$ & $\begin{array}{c}\text { Percentage } \\
\text { with damaged } \\
\text { or modified } \\
\text { apical ridge }\end{array}$ & $\begin{array}{c}\text { Percentage with } \\
\text { missing apical } \\
\text { ridge or lost } \\
\text { acrosomal cap }\end{array}$ \\
\hline Formaldehyde & $86.7 \pm 3.47$ & $9.2 \pm 3.59$ & $4.0 \pm 0.41$ \\
Glutaraldehyde & $88.0 \pm 4.20$ & $11.0 \pm 4.16$ & $1.0 \pm 0.58$ \\
Eosin-nigrosin/Giemsa & $88.7 \pm 2.33$ & $9.0 \pm 2.08$ & $2.3 \pm 0.86$ \\
FITC-PSA & $85.0 \pm 3.03$ & $11.0 \pm 3.0$ & $4.2 \pm 0.48$ \\
\hline
\end{tabular}

Values are means \pm SEM. Assessments were made on independent samples ( $n=4$ males).

*Fluorescein isothiocyanate conjugated to the lectin Pisum satioum.

reveal a lower proportion of normal spermatozoa (with a slight increase in abnormalities in the flagellum), but the differences were not significant.

Acrosome integrity was assessed using four different methods. Spermatozoa were either fixed with formaldehyde or glutaraldehyde and examined with phase contrast optics $(\times 1000)$, or they were stained with either eosin-nigrosin/ Giemsa or FITC-PSA. Smears stained with eosin-nigrosin/ Giemsa were examined using bright field illumination $(\times 1000)$, whereas FITC-PSA-stained smears were examined using fluorescence microscopy $(\times 1000)$. Assessment of semen samples with these four methods revealed similar percentages of spermatozoa with normal apical ridges, and also in the other two categories (that is, damaged apical ridge or acrosomal cap and missing apical ridge or lost acrosomal cap) (Table 2).

These results indicate that the different methods used to examine sperm morphology and acrosome integrity gave similar results in our laboratory. For practical reasons, further work was carried out staining spermatozoa with eosinnigrosin/Giemsa.

\section{Characteristics of the ejaculate in three species of gazelle}

Semen was collected from G. dama, G. dorcas and G. cuvieri, and various semen parameters were quantified; a summary of results is shown (Table 3). Analyses of volume, sperm concentration, and total sperm counts showed some clear trends, although there were no significant differences between species, probably due to the high variation found between individuals. The following trends were noted. Average volume of semen collected was highest in $G$. dama compared with $G$. cuvieri and $G$. dorcas, but volume in the latter two species was more variable. The volume of the ejaculate in $G$. dama varied between 565 and $5569 \mu \mathrm{l}$, in $G$. dorcas between 0 and $1454 \mu \mathrm{l}$ (one male produced no semen), and in G. cuvieri, it had a range between 50 and $1411 \mu$ l. Concentration of spermatozoa also showed variation between ejaculates (G. dama: 14-1629 $\times$ $10^{6} \mathrm{ml}^{-1}, \mathrm{G}$. dorcas: $197-2836 \times 10^{6} \mathrm{ml}^{-1}, \mathrm{G}$. cuvieri: $228-$ $927 \times 10^{6} \mathrm{ml}^{-1}$ ) with $G$. dorcas having the highest average sperm concentration of the three species. The total sperm count (that is, total number of spermatozoa per ejaculate) was highest in $G$. dama and similar between $G$. dorcas and $G$. cuvieri.

Motility (assessed subjectively) and viability (assessed with eosin-nigrosin) were high in the three species. However, there were two occasions (one with G. dorcas and one with G. cuvieri) when semen showed no motility upon collection, and thus data from these individuals were not included in further analyses.

There were significant differences in the proportion of normal spermatozoa between species, with $G$. dama having a lower proportion of normal spermatozoa (see Table 3). $G$. dorcas and $G$. cuvieri appeared to have a higher proportion of spermatozoa with normal acrosomes than $G$. dama, but the differences did not reach significance. 
Table 3. Semen characteristics in three species of gazelles (genus Gazella)

\begin{tabular}{|c|c|c|c|}
\hline Parameter & G. dama mhorr & G. dorcas neglecta & G. cuvieri \\
\hline Volume $(\mu \mathrm{l})$ & $1505.9 \pm 593.03$ & $535.9 \pm 183.94$ & $773.4 \pm 181.66$ \\
\hline Concentration $\left(\times 10^{6} \mathrm{ml}^{-1}\right)$ & $646.6 \pm 190.18$ & $922.1 \pm 332.36$ & $483.8 \pm 79.48$ \\
\hline Total sperm count $\left(\times 10^{6}\right)$ & $984.4 \pm 394.33$ & $446.7 \pm 112.82$ & $444.9 \pm 137.77$ \\
\hline Wave motion $(0-5)$ & $2.4 \pm \quad 0.65$ & $2.9 \pm \quad 0.74$ & $2.4 \pm \quad 0.62$ \\
\hline Individual motility (\%) & $70.6 \pm 12.07$ & $53.4 \pm 15.69$ & $61.6 \pm 13.61$ \\
\hline Progressive motility $(\%)^{a}$ & $58.1 \pm 12.22$ & $49.5 \pm 15.70$ & $43.5 \pm 12.14$ \\
\hline Quality of progressive motility $(0-5)$ & $2.9 \pm \quad 0.48$ & $2.9 \pm 0.63$ & $2.6 \pm \quad 0.60$ \\
\hline Viability $(\%)^{\mathrm{b}}$ & $71.2 \pm 8.86$ & $76.5 \pm 10.98$ & $78.3 \pm 1.96$ \\
\hline \multicolumn{4}{|l|}{ Morphology $(\%)^{c}$} \\
\hline Normal & $59.5 \pm 6.81$ & $80.6 \pm 7.21$ & $77.6 \pm$ \\
\hline Abnormal head & $10.5 \pm 3.89$ & $2.5 \pm 1.29$ & $5.0 \pm$ \\
\hline Abnormal midpiece & $3.0 \pm \quad 0.88$ & $1.0 \pm 0.33$ & $1.5 \pm$ \\
\hline Abnormal principal/terminal piece & $13.8 \pm \quad 4.06$ & $14.0 \pm 6.97$ & $8.4 \pm \quad 1.33$ \\
\hline Coiled tail & $1.1 \pm \quad 0.44$ & $0.2 \pm \quad 0.15$ & $1.2 \pm$ \\
\hline Cytoplasmic droplet & $12.1 \pm 2.31$ & $1.7 \pm 0.56$ & $6.1 \pm \quad 2.20$ \\
\hline \multicolumn{4}{|l|}{ Acrosome integrity $(\%)^{d}$} \\
\hline NAR & $68.3 \pm 11.33$ & $80.4 \pm$ & $78.7 \pm 7.90$ \\
\hline DAR & $11.1 \pm \quad 2.23$ & $12.1 \pm \quad 3.72$ & $17.2 \pm \quad 5.77$ \\
\hline MAR & $19.9 \pm 11.13$ & $7.5 \pm 2.96$ & $5.2 \pm \quad 2.08$ \\
\hline
\end{tabular}

Values are means \pm SEM. Assessments were made on independent ejaculates of $G$. dama $(n=8)$, G. dorcas $(n=7)$ and $G$. cuvieri $(n=8)$. Values from one ejaculate each of $G$. dorcas and $G$. cuvieri were eliminated before analyses due to lack of sperm motility.

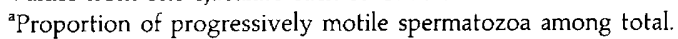

${ }^{b}$ Assessed by staining with eosin-nigrosin.

'Assessed by staining with eosin-nigrosin/Giemsa. Differences between species:

Proportion of normal spermatozoa: ANOVA, $F(2,20)=3.91, P=0.04$, Fisher's post-hoc test: $G$. dama $G$. dorcas, $P=0.02$, G. dama G. cuvieri, $P=0.04, G$ cuvieri $G$. dorcas, n.s.

Proportion with abnormal heads: ANOVA, $F(2,20)=2.70$, n.s., Fisher's post-hoc test: $G$. dama $G$. dorcas, $P=0.03, G$. dama G. cuvieri, n.s., G. cuvieri G. dorcas, n.s.

Proportion of abnormal midpieces: ANOVA, $F(2,20)=3.22, P=0.06$; Fisher's post-hoc test: $G$. dama $G$. dorcas, $P=0.02$, G. dama G. cuvieri, n.s., G. dorcas G. cuvieri, n.s.

Proportion of spermatozoa with cytoplasmic droplet: ANOVA, $F(2,20)=8.51, P=0.002$, Fisher's post-hoc test: $G$. dama $G$. dorcas, $p=0.0005$, G. dama G. cuvieri, $P=0.04, G$. dorcas $G$. cuvieri, $P=0.06$. (n.s., not significant).

${ }^{\mathrm{d}}$ Assessed by staining with Giemsa. NAR = normal apical ridge; DAR = damaged or modified apical ridge; $\mathrm{MAR}=$ missing apical ridge or lost acrosomal cap.

\section{Sperm morphology and dimensions in the three species of gazelle}

The sperm heads of G. dama and G. cuvieri were pear-shaped, whereas sperm heads in $G$. dorcas were oval (Fig. 1). Dimensions of sperm components are shown (Table 4). It can be seen that spermatozoa from the three species differ when the various sperm components are considered. Average total length of spermatozoa from $G$. dama and $G$. dorcas was significantly less than that in spermatozoa from $G$. cuvieri. This difference was due essentially to a shorter head in spermatozoa from $G$. dorcas and a shorter flagellum in spermatozoa from G. dama.

Analyses of the ratio between head length and width revealed clear differences between species (Table 5). It is noteworthy that this ratio differed between G. dama and G. cuvieri since, at first glance, the sperm heads in these two species appear to have a similar overall shape (that is, both are pear-shaped) (see Fig. 1). Comparisons between species, taking into account the ratio of length of the midpiece to the total length of the flagellum, revealed that spermatozoa from $G$. dama had a shorter midpiece when compared with spermatozoa from G. cuvieri or G. dorcas (Table 5).

Average values of head or tail components for all the individuals of each species were plotted (Fig. 2). Comparisons of all the individuals show that variation in average sperm dimensions within species was considerable, both with regards to sperm heads and flagellae. It is interesting to note that the two species with similar sperm heads (G. dama and G. cuvieri) could be clearly distinguished when the dimensions of components of their flagella were plotted (Fig. 2b).

\section{Semen characteristics, testes mass and bodyweight}

The three species have clear differences in body size and bodyweight (Table 6); G. dama is larger than G. cuvieri which, in turn, is larger than G. dorcas. A comparison of the eight males of each species included in the sample revealed that these differences were highly significant (Table 6).

If testes size and, therefore, sperm production, are a by product of differences in body size between the three species, it would be expected that testes size, ejaculate volume, and total number of spermatozoa would show clear differences that would be in the same direction as differences in body weight, that is, G. dama > G. cuvieri > G. dorcas. In agreement with this hypothesis, testes mass was larger in $G$. dama than in $G$. cuvieri which, in turn, had larger testes than G. dorcas; these differences were significant (Table 6). However, none of the 
(a)

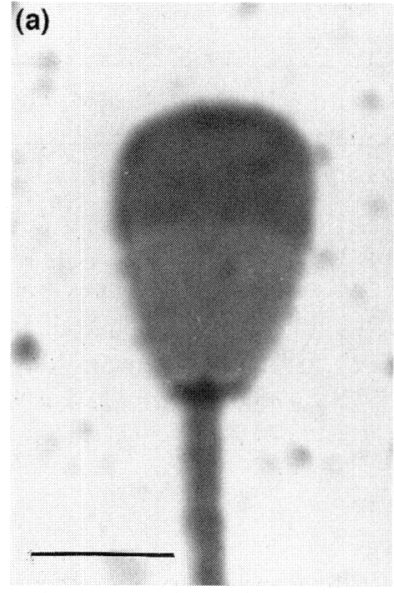

(b)

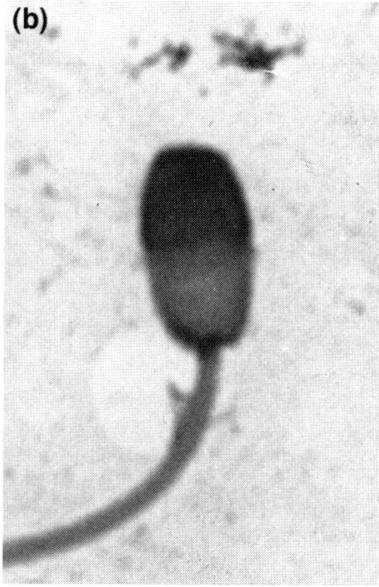

(c)

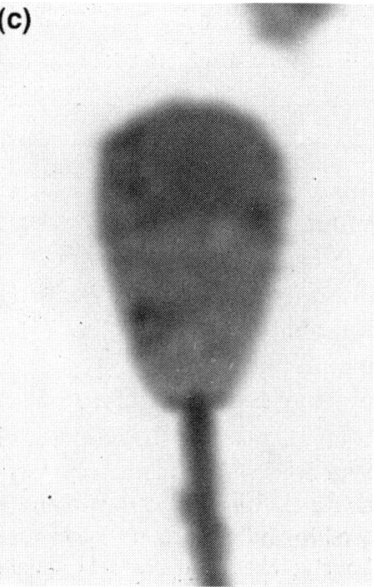

Fig. 1. Morphology of sperm heads of (a) Gazella dama mhorr, (b) G. dorcas neglecta and (c) G. cuvieri. Scale bar represents $5 \mu \mathrm{m}$.

Table 4. Dimensions of spermatozoa in three species of gazelle*

\begin{tabular}{|c|c|c|c|c|c|}
\hline Species & $\begin{array}{l}\text { Head } \\
\text { length }\end{array}$ & $\begin{array}{l}\text { Head } \\
\text { width }^{c}\end{array}$ & $\begin{array}{l}\text { Midpiece } \\
\text { length }^{e}\end{array}$ & $\begin{array}{l}\text { Length of principal/ } \\
\text { terminal piece }\end{array}$ & $\begin{array}{l}\text { Total } \\
\text { length }\end{array}$ \\
\hline Gazella dama mhorr & $9.5 \pm 0.13$ & $6.5 \pm 0.08$ & $9.4 \pm 0.09^{f}$ & $44.2 \pm 0.74^{h}$ & $63.1 \pm 0.90$ \\
\hline Gazella dorcas neglecta & $7.2 \pm 0.11^{b}$ & $4.0 \pm 0.08^{d}$ & $10.7 \pm 0.12^{\mathrm{f}}$ & $46.5 \pm 0.7 \mathrm{I}^{\mathrm{h}}$ & $64.4 \pm 0.69$ \\
\hline Gazella cuvieri & $9.7 \pm 0.09$ & $6.3 \pm 0.07$ & $11.1 \pm 0.17^{\mathrm{f}}$ & $47.5 \pm 0.83^{h}$ & $68.4 \pm 0.92$ \\
\hline
\end{tabular}

\footnotetext{
*Spermatozoa were smeared and stained with eosin-nigrosin/Giemsa. Twenty-five spermatozoa from each individual were measured and averaged. Averages of the different individuals were used to calculate the average for each species. Data $(\mu \mathrm{m})$ are means \pm SEM ( $n=8$ individuals for $G$. dama and $G$. cuvieri and 7 for $G$. dorcas). Data were log-transformed and analysed using analysis of variance.

${ }^{2}$ ANOVA: $F(2,20)=162.07, P<0.0001$. ' $D$ ifferent from the other two species; Fisher's post-hoc test, $P<0.0001$.

'ANOVA: $F(2,20)=372.94, P<0.0001$. 'Different from the other two species; Fisher's post-hoc test, $P=0.0001$.

'ANOVA: $F(2,20)=54.57, P<0.0001$. 'Different from the other two species; Fisher's post-hoc test, $P<0.05$.

${ }^{8}$ ANOVA: $F(2,20)=5.16, P=0.02 .{ }^{h}$ Different from the other two species; Fisher's post-hoc test, $P<0.05$.

'ANOVA: $F(2,20)=10.89, P=0.0006$. 'Different from the other two species; Fisher's post-hoc test, $P<0.005$.
}

ejaculate parameters that have been assumed to correlate with testes mass were significantly different between the three species, although ejaculate volume did follow the predicted trend (see Table 3).

\section{Characteristics of the ejaculate and sperm competition}

The theory of sperm competition proposes that sperm competition selects for an increase in testes size (in relation to bodyweight), ejaculate volume, number of spermatozoa per ejaculate, and the proportion of motile spermatozoa, as well as an elongation of the spermatozoon.

Relative testes mass was used as an indicator of the mating system in an attempt to deduce whether the three species under study experience sperm competition. Thus, the data on bodyweight and testis mass of these three species, together with data available for other ungulates (Ginsberg and Rubenstein, 1990), were analysed to determine whether the size of their testes is larger or smaller than that predicted by their body size. As shown in Fig. 3, G. dorcas is located above the regression line, suggesting that it does experience sperm competition, while G. cuvieri has testes of the size predicted by allometric relationships, and G. dama falls below the line, suggesting that it does not experience sperm competition. Thus, this hypothesis predicts that differences in the above mentioned variables should be in the following direction: G. dorcas > G. cuvieri > G. dama.

Differences in gonadosomatic index (testis mass/ bodyweight) between the three species were highly significant (Table 6), and the differences followed the above prediction, that is, G. dorcas has a higher gonadosomatic index than $G$. cuvieri which, in turn, has a higher index than $G$. dama (Table 6). However, despite these clear differences in relative testis mass, no significant differences were found in ejaculate volume, total number of spermatozoa per ejaculate, or proportion of motile spermatozoa.

One ejaculate parameter did show significant differences between the three species: the proportion of normal spermatozoa (see Table 3). This proportion was slightly, but not significantly, higher in G. dorcas than in G. cuvieri, and was significantly higher in these two species than in $G$. dama. Within the morphologically abnormal spermatozoa, several different types of abnormality showed significant differences: the proportion of spermatozoa with abnormal heads, abnormal midpieces, and cytoplasmic droplets was higher in G. dama 
Table 5. Ratios between sperm components in three species of gazelle*

\begin{tabular}{lcc}
\hline Species & $\begin{array}{c}\text { Head } \\
\text { length/width }\end{array}$ & $\begin{array}{c}\text { Midpiece/total } \\
\text { flagellum }\end{array}$ \\
\hline Gazella dama mhorr & $1.47 \pm 0.012^{\mathrm{b}}$ & $0.17 \pm 0.002^{\mathrm{d}}$ \\
Gazella dorcas neglecta & $1.81 \pm 0.015^{\mathrm{b}}$ & $0.19 \pm 0.003$ \\
Gazella cuvieri & $1.55 \pm 0.026^{\mathrm{b}}$ & $0.19 \pm 0.003$
\end{tabular}

*Twenty-five spermatozoa from each individual were measured. The ratios between head length and width and between midpiece and total flagellum were calculated for each spermatozoon. Average values were then obtained for each individual ( $n=8$ individuals for $G$. dama and G. cuvieri and $n=7$ for $G$. dorcas) and these were then averaged to find mean \pm SEM values for each species. Data were $\log$-transformed and analysed using analysis of variance.

${ }^{a}$ ANOVA: $F(2,20)=77.74, P<0.0001$. 'Different from the other two species; Fisher's post-hoc test; $P<0.003$.

'ANOVA: $F(2,20)=8.48, P=0.002 .{ }^{d}$ Different from the other two species; Fisher's post-hoc test, $P<0.007$
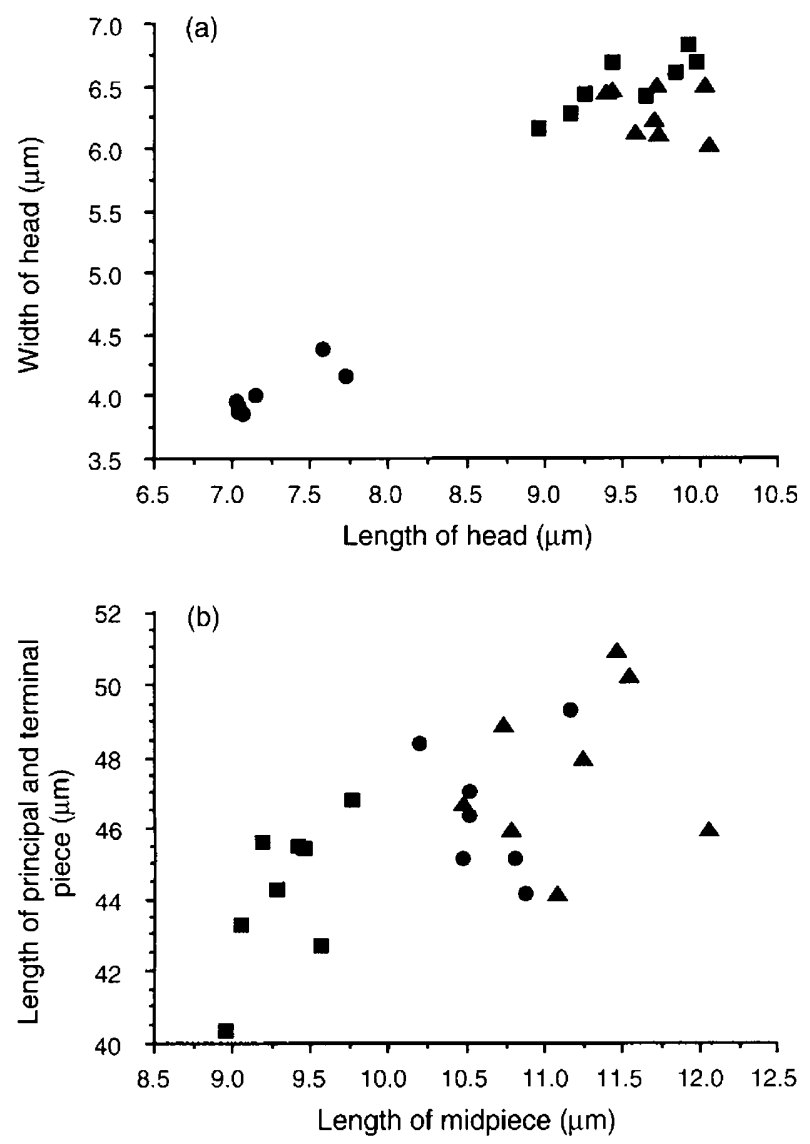

Fig. 2. Dimensions of (a) the head and (b) the flagellum of spermatozoa from individuals of $(\boldsymbol{\square})$ G. dama, ( $)$ G. dorcas and ( $\boldsymbol{\Delta}$ ) G. cuvieri.

than in $G$. dorcas. The proportion of spermatozoa with cytoplasmic droplets was also higher in G. dama than in G. cuvieri, and the proportion in the latter was, in turn, higher than that found in $G$. dorcas (see Table 3). Thus, all the differences were in the direction predicted by the theory of sperm competition, and most of the significant differences were between the two species with the highest and lowest intensity of sperm competition (that is, $G$. dorcas and $G$. dama).

The length of spermatozoa was significantly longer in G. cuvieri than in the other two species (Table 5). The length of the flagellum is longest in G. cuvieri, intermediate in $G$. dorcas and shortest in $G$. dama. Thus, while the species with the least sperm competition ( $G$. dama) has the shortest spermatozoa and the shortest flagellum, the differences between the other two species do not fit predictions derived from sperm competition theory. However, these two species differ in the shape and dimensions of their sperm heads, and it is possible that these differences have an impact on sperm hydrodynamics and, in turn, on sperm motility.

\section{Characteristics of the ejaculate and inbreeding}

Owing to differences in the number of individuals in founder populations, the three populations of gazelle differed in the level of inbreeding. In our sample, the mean coefficient of inbreeding was significantly higher in G. dama and G. cuvier than in G. dorcas, and was not significantly higher in G. cuvieri than in G. dama (Table 6). If inbreeding does affect semen characteristics, such as the proportion of normal spermatozoa in the ejaculate (see Wildt et al., 1983, 1987; O'Brien et al, 1985), the prediction would be that the proportion of normal spermatozoa would follow the trend: $G$. dorcas $>$ G. dama $\geq$ G. cuvieri.

The inter-specific differences described above do not seem to fit this prediction: there are no significant differences between $G$. dorcas and $G$. cuvieri in the proportion of normal spermatozoa, despite the fact that $G$. dorcas shows the lowest level of inbreeding and G. cuvieri the highest. Furthermore, $G$. cuvieri males have a significantly higher proportion of normal spermatozoa than $G$. dama males (Table 3), even though G. cuvieri males tend to have higher levels of inbreeding (Table 6).

\section{Discussion}

In the work described here the semen characteristics in three species of gazelle (Gazella dama mhorr, G. dorcas neglecta and G. cuvieri), which are part of a breeding programme for the establishment of genetic resource banks, were examined and factors that may influence the quality of ejaculates in these species were analysed.

The study of ejaculate quality involved the assessment of viability, sperm motility, cell morphology and acrosomal status. Several methods have been used previously to distinguish between live and dead cells, such as the eosin-nigrosin stain (Hancock, 1951), or the fluorescent probes propidium iodide (Garner et al., 1986; Harrison and Vickers, 1990) or Hoechst 33258 (De Leeuw et al., 1991). In preliminary experiments, we found that use of the fluorescent probe Hoechst 33258 resulted in a proportion of stained spermatozoa that was lower than that observed after staining with eosin-nigrosin or eosin-nigrosin/Giemsa (J. Cassinello and E. R. S. Roldan, unpublished data). This result has also been observed by other authors (Centola et al., 1990; Tamuli and Watson, 1994) and could be due to a slight toxic effect of the fluorescent dye 
Table 6. Bodyweights, testes masses and inbreeding in three species of gazelles (genus Gazella)*

\begin{tabular}{lccc}
\hline Parameter & G. dama mhorr & G. dorcas neglecta & G. cuvieri \\
\hline Bodyweight $(\mathrm{kg})^{\mathrm{a}}$ & $58.22 \pm 1.23$ & $15.62 \pm 0.52$ & $34.12 \pm 0.66$ \\
${\text { Testes masses }(\mathrm{g})^{\mathrm{b}}}_{\text {Gonadosomatic index }^{\mathrm{c}}}$ & $43.06 \pm 3.61$ & $31.46 \pm 2.09$ & $39.37 \pm 2.42$ \\
Inbreeding coefficient $^{\mathrm{d}}$ & $0.00074 \pm 0.00006$ & $0.00201 \pm 0.00012$ & $0.00116 \pm 0.00008$ \\
& $0.1257 \pm 0.0314$ & $0.0229 \pm 0.0116$ & $0.1430 \pm 0.0217$ \\
\hline
\end{tabular}

*Values are means \pm SEM $(n=8$ individuals of each species).

aANOVA, $F(2,21)=702.24, P<0.0001$. Fisher's post-hoc test for all three combinations $P<0.0001$.

'ANOVA, $F(2,21)=4.42, P=0.02$. Fisher's post-hoc test, $G$. dama $G$. dorcas, $P=0.01$, G. dorcas $G$. cuvieri, $P=0.04, G$. dama G. cuvieri, n.s.

'Testes mass $(\mathrm{g})$ bodyweight $(\mathrm{g})$; ANOVA, $F(2,21)=53.86, P<0.0001$. Fisher's post-hoc test for all three combinations $P<0.005$.

'ANOVA, $F(2,21)=8.88, P=0.002$. Fisher's post-hoc test, $G$. dama $G$. dorcas, $P=0.003, G$. dorcas $G$. cuvieri, $P=0.0008$,

G. dama G. cuvieri, n.s.

n.s., not significant.

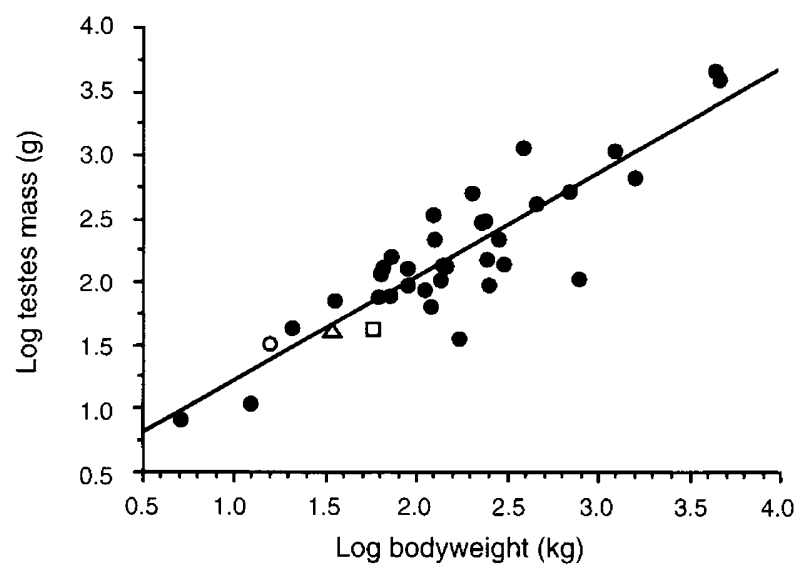

Fig. 3. Relation between testes mass and bodyweight in ungulate species, including $(\square)$ Gazella dama, $(\bigcirc)$ G. dorcas and $(\triangle)$ G. cuvieri. Data on bodyweight and testes mass for species other than gazelles (-) are from Ginsberg and Rubenstein (1990). Regression equation: $y=0.815 x+0.409 ; r^{2}=0.784, P<0.0001$.

(Woelders, 1991). In the present study, eosin-nigrosin stain gave good quality preparation and we, therefore, used this method for our evaluation of sperm viability in gazelles. No differences were found in the proportion of live cells when staining with eosin-nigrosin and further staining with Giemsa.

Sperm morphology and acrosome integrity have been evaluated using a variety of methods, including phase contrast examination of formaldehyde- or glutaraldehyde-fixed samples (Pursel and Johnson, 1974; Johnson et al., 1975), Giemsa staining (Watson, 1975) or fluorochrome-labelled lectins (Cross and Meizel, 1989). In an initial series of experiments, we compared methods for quantifying sperm cell morphology and acrosome integrity. Glutaraldehyde fixation consistently gave good preparations with high definition. Formaldehyde was used at a lower concentration $(0.1 \%)$, similar to that used for counting spermatozoa in a haemocytometer. This concentration of formaldehyde is sufficient to immobilize spermatozoa (c.f. Dott and Foster, 1975); however, it is not clear whether it would fix sperm cells (c.f. Dort et al.., 1976). Although there appeared to be slight differences (though not significant) when sperm morphology was examined (that is, slightly lower percentages of normal heads in formaldehyde-treated spermatozoa), no differences were found between fixation with formaldehyde or glutaraldehyde when acrosomal integrity was assessed. Furthermore, there were no differences between these two methods and staining with eosin-nigrosin or FITC-PSA.

The eosin-nigrosin/Giemsa staining (Tamuli and Watson, 1994) proved to be very useful, and simpler than that described by Talbot and Chacon (1981). This technique allowed for the distinction of live-dead spermatozoa and also acrosomal status: therefore, four categories could be distinguished (that is, live acrosome-intact, live acrosome-reacted/damaged, dead acrosome-intact, and dead acrosome-reacted/damaged) that would be very useful for functional tests of the ability of gazelle spermatozoa to fertilize.

However, there is little information on sperm dimensions in Artiodactyla. It is also difficult to compare dimensions of spermatozoa between species studied previously and the species of gazelle examined here owing to differences in the source of specimens, and the way in which they were processed and analysed. For example, sperm dimensions of several ungulate species examined by Morgenthal (1967) have been found in later studies to be underestimates (Watson, 1976; Cummins and Woodall, 1985), and it has been argued that the differences could be due to the fact that epididymal spermatozoa were used in the earlier studies. However, some comparisons are possible between our results and dimensions of spermatozoa from some ungulate species collected recently using more accurate methods. Furthermore, it is feasible to make comparisons with existing information on sperm head morphology in ungulates.

The morphology of the sperm heads in the three species of gazelles studied here depart somewhat from the pattern seen in most bovids where heads are usually paddle-shaped (Morgenthal, 1967; Watson, 1976; Gosch et al., 1989). Two of the gazelle species studied in the present work ( $G$. dama and G. cuvieri) had pear-shaped sperm heads and their maximum width (near the apical edge) was higher than that seen in other related species (see Cummins and Woodall, 1985); spermatozoa from $G$. dorcas had oval heads and both head length and width were smaller than those seen in related bovids (see Cummins and Woodall, 1985). This type of sperm head may have an 
important impact on the hydrodynamics and motion characteristics of the sperm cell of this species, since it has been found that motility is affected by subtle changes in the sperm head (Dresdner and Katz, 1981).

The dimensions of spermatozoa from $G$. dama and $G$. dorcas, based on measurements of a limited number of cells and individuals, have been reported previously. There is good agreement between dimensions of $G$. dorcas reported by Howard et al. (1983) and the results obtained in the study reported here. There seems to be some agreement with data previously published for G. dama (Holt et al., 1996a) (that is, data on sperm head dimensions show agreement), but comparisons are not possible for all sperm components since data on tail length previously presented do not discriminate values for midpiece from those of principal piece plus terminal piece. The spermatozoa of $G$. cuvieri have not been examined before, and it was found that their total length was greater than that seen in the other two species of gazelle; this was due to a longer midpiece and principal/terminal piece.

There are no detailed studies in ungulates about interindividual variations in the dimensions of sperm components, since most studies have dealt with, and presented average values for, different species. Our study has revealed that there is a considerable variation in head and flagellum dimensions between individuals in each of the three species examined.

Differences in semen characteristics between species have been widely reported, but our understanding of the causal factors that generate such differences is still poor. The lack of knowledge about these causal factors makes it difficult to evaluate ejaculate 'quality' when confronted, as in this study, with endangered species about which little is known. Are differences between species due to selective forces that have operated for a long time upon wild populations (for example, sperm competition), or are they due to negative factors imposed by human intervention which we should try to eradicate (for example, inbreeding)? To address this issue we have considered three of the main factors that may influence semen quality: body size, sperm competition and inbreeding. Each of these hypotheses yields different predictions, making it possible to distinguish clearly between them.

The first hypothesis states that differences in testes size and semen characteristics are a by-product of differences in body size. Organ size tends to scale allometrically with body size, and testes size is no exception (Kenagy and Trombulak, 1986). Since the three species under study show clear differences in body size, some differences in ejaculate features may be a consequence of such allometric relationships. Body size is likely to influence testes size which, in turn, is assumed to determine the amount of spermatogenic tissue and, thus, sperm production rates and the total number of spermatozoa per ejaculate.

Therefore, the prediction derived from the first hypothesis (that testes size and semen characteristics are a byproduct of body size) would be that testes size, and those semen characteristics likely to be associated with differences in size such as ejaculate volume and total number of spermatozoa, would show inter-specific differences in the following direction: $G$. dama $>G$. cuvieri $>G$. dorcas. Although differences in testes size between the three species are clearly related to differences in body size, none of the ejaculate parameters that have been assumed to correlate with testes size showed significant differences. Differences in ejaculate volume did follow the predicted direction, but the differences did not reach statistical significance. The lack of differences in the total number of spermatozoa implies that an increase in testes size per se does not necessarily mean that sperm production rate increases accordingly.

The second hypothesis proposes that differences between the three gazelle species are the result of differences in the intensity of sperm competition. Sperm competition is a potent selective force that has favoured the evolution of some important reproductive traits among male mammals, such as an increase in testes size, ejaculate volume, total number of spermatozoa per ejaculate and, according to some studies, a greater proportion of motile spermatozoa (Harcourt et al., 1981; Kenagy and Trombulak, 1986; Møller, 1988; Harcourt, 1991; reviewed in Gomendio and Roldan, 1993a; Gomendio et al., 1998). Sperm competition has also influenced the evolution of sperm dimensions, since polyandrous species (that is, species in which females copulate with more than one male in each sexual cycle) have longer spermatozoa than monandrous species (that is, females that have one sexual partner per cycle) (Gomendio and Roldan, 1991).

A comparative analysis of data for 37 species of ungulates showed that $G$. dorcas has large testes in relation to its body size; $G$. cuvieri has testes of the size predicted by its body size, and $G$. dama has small testes in relation to its body size. The relationship between relative testes size and sperm competition is so strong that the former can be used as a reliable indicator of the intensity of sperm competition (Harcourt et al, 1981; Gomendio et al., 1998). Thus, the intensity of sperm competition is likely to be high in $G$. dorcas, intermediate in $G$. cuvieri and low in G. dama. According to theoretical models, sperm competition should favour an increase in the total number of spermatozoa per ejaculate and, in fact, this is the main explanation for the increase in relative testes size with sperm competition. We found no differences in the total number of spermatozoa between the three species, in contradiction to earlier reports (Møller, 1988). In a comparative analysis of 20 species of primate, Møller (1988) reported that relative testes size was also related to the proportion of motile spermatozoa. We found no relationship. Our results are in agreement with a recent re-analysis of Møller's data which show that, when phylogenetic effects are removed, the relationships linking relative testes size with sperm number and motile spermatozoa disappear (Gomendio et al., 1998). However, in the present study, the percentage of normal spermatozoa did show significant differences in the direction predicted by sperm competition: $G$. dorcas had a higher proportion of normal spermatozoa than $G$. cuvieri which, in turn, was higher than in $G$. dama. This finding suggests that the proportion of normal spermatozoa is an important determinant of the success of ungulate ejaculates under sperm competition.

Inter-species differences in sperm dimensions did not seem to support the hypothesis that sperm competition favours an increase in sperm length (and in particular in the length of the flagellum) (Gomendio and Roldan, 1991). It is possible that the differences in sperm dimensions are confounded by the influence of female reproductive traits (Gomendio and Roldan 1993 b), which could not be accounted for in this study. 
The third hypothesis predicted that high levels of inbreeding would reduce semen quality, affecting mainly the proportion of normal spermatozoa, as has been postulated for carnivores (Wildt et al., 1983, 1987; O'Brien et al., 1985). The results presented here do not support this prediction, because the differences found in the proportion of normal spermatozoa did not follow the direction defined by differences in levels of inbreeding. Thus, no differences were found between the species with the highest (G. cuvieri) and lowest (G. dorcas) levels of inbreeding, and $G$. cuvieri had a higher proportion of normal spermatozoa than $G$. dama despite having higher levels of inbreeding. No effects of inbreeding on other semen characteristics were detected despite clear differences in levels of inbreeding between the three species. There are several possible interpretations: (a) inbreeding does not have the same effect among ungulates as among carnivores; (b) whether inbreeding does or does not decrease ejaculate quality depends on whether the deleterious alleles were present in the founder population; (c) mean values of inbreeding and of semen characteristics obscure underlying differences between individuals that may well reflect the predicted trends. More data will be needed to distinguish between these alternative explanations.

In conclusion, the study presented here has allowed us to characterize semen characteristics in endangered species of gazelle that are part of the breeding programme at the EEZA, and to postulate that differences in semen characteristics may be due, at least in part, to differences in the intensity of sperm competition. These results highlight the importance of understanding the evolutionary and causal factors that influence semen characteristics in endangered species, and their implications for the establishment of genetic resource banks.

This work was supported by DGICYT (PB 93-0186) and DGES (PB 96-0880). The authors thank $M$. Cano for permission to study the gazelles and for access to the facilities available at the EEZA; $G$. Espeso for veterinary expertise and assistance with semen collection; M. A. Barros for assistance with semen collection and analyses of the samples; the staff of the EEZA for expert handling of the animals; J. de la Fuente for access to image analysis equipment; S. Perez-Garnelo for guidance with the use of image analysis equipment to obtain sperm dimensions; and B. Pintado for critically reading the manuscript.

\section{References}

Abaigar T (1993) Gazella dorcas neglecta Studbook. Cuadernos Monográficos 22. Instituto de Estudios Almerienses, Almería

Alados CL and Escos J (1991) Phenotypic and genetic characteristics affecting lifetime reproductive success in female Cuvier's, dama and dorcas gazelles (Gazella cuvieri, G. dama and G. dorcas) Journal of Zoology (London) 223 307-321

Alados CL, Escos J and Vericad JR (1988) Captive populations of Northwest African Antilopinae and Caprinae at the Estacion Experimental de Zonas Aridas. In Conservation and Biology of Desert Antelopes Eds A Dixon and D Jones pp 199-211. Christopher Helm, Bromley

Boever J, Knox D, Merilan C and Read B (1980) Estrus induction and artificial insemination with successful pregnancy in Speke's gazelle. Proceedings 9th International Congress on Animal Reproduction and Artifcial Insemination, Madrid 2 565-569

Cano M (1991) El Antílope Mohor Gazella ( = Nanger) dama mhorr Bennett 1832 en Cautividad. Taxonomía, Biologia, Ecología, Etología, Técnicas de Salvamento y Reintroducción, y Posibilidades de Aprovechamiento Económico PhD Thesis, Universidad de Granada
Centola GM, Mattox JH, Burde S and Leary JF (1990) Assessment of viability and acrosome status of fresh and frozen thawed human spermatozoa using single wave-fluorescence microscopy Molecular Reproduction and Development $27 \quad 130-135$

Cross NL and Meizel S (1989) Methods for evaluating the acrosomal status of mammalian sperm Biology of Reproduction 41 635-641

Cummins JM and Woodall PF (1985) On mammalian sperm dimensions Journal of Reproduction and Fertility $\mathbf{7 5} \quad \mathbf{1 5 3}-175$

De Leeuw AM, Den Daas JHG and Woelders H (1991) The fix vital stain method: simultaneous determination of viability and acrosomal status of bovine spermatozoa Journal of Andrology 12 112-118

Dott HM and Foster GC (1975) Preservation of differential staining of spermatozoa by formol citrate Journal of Reproduction and Fertility 45 57-60

Dott HM, Moor RM and Polge C (1976) Artificial insemination with spermatozoa in formaldehyde Journal of Reproduction and Fertility 46277

Dresdner RD and Katz DF (1981) Relationship of mammalian sperm motility and morphology to hydrodynamic aspects of cell function Biology of Reproduction 25 920-930

Ebenhard T (1995) Conservation breeding as a tool for saving animal species from extinction Trends in Ecology and Evolution 10 438-443

Escos J (1992) Gazella cuvieri Studbook Cuadernos Monográficos 20. Instituto de Estudios Almerienses, Almería

Garland P (1989) Artificial insemination of scimitar-horned oryx (Oryx dammah) Bulletin Zoo Management 27 29-30

Garner DL, Pinkel D, Johnson LA and Pace MM (1986) Assessment of spermatozoal function using dual fluorescent staining and flow cytometric analyses Biology of Reproduction 34 127-138

Ginsberg JR and Rubenstein DI (1990) Sperm competition and variation in zebra mating behavior Behavioral Ecology and Sociobiology 26 427-434

Gomendio M and Roldan ERS (1991) Sperm competition influences sperm size in mammals Proceedings of the Royal Society of London Series B 243 181-185

Gomendio M and Roldan ERS (1993a) Mechanisms of sperm competition: linking physiology and behavioural ecology Trends in Ecology and Evolution 8 95-100

Gomendio M and Roldan ERS (1993b) Co-evolution between male ejaculates and female reproductive biology in eutherian mammals Proceedings of the Royal Society of London Series B 252 7-12

Gomendio M, Harcourt AH and Roldan ERS (1998) Sperm competition in mammals. In Sperm Competition and Sexual Selection Eds TR Birkhead and AP Moller. Academic Press, London (in press)

Gosch B, Bartolomaeus T and Fischer K (1989) Light and electron microscopy of fallow deer (Dama dama) spermatozoa Journal of Reproduction and Fertility $\mathbf{8 7}$ 187-192

Hancock JL (1951) A staining technique for the study of temperature shock in semen Nature 167323

Harcourt AH (1991) Sperm competition and the evolution of nonfertilizing sperm in mammals Evolution 45 314-328

Harcourt AH, Harvey PH, Larson SG and Short RV (1981) Testis weight, body weight and breeding system in primates Nature, London 293 55-57

Harcourt AH, Purvis A and Liles L (1995) Sperm competition: mating system, not breeding season, affects testes size of primates Functional Ecology 9 468-476

Harrison RAP and Vickers SE (1990) Use of fluorescent probes to assess membrane integrity in mammalian spermatozoa Journal of Reproduction and Fertility 88 343-352

Holt WV, Moore HDM, North RD, Hartman TD and Hodges JK (1988) Hormonal and behavioural detection of oestrus in blackbuck, Antilope cervicapra, and successful artificial insemination with fresh and frozen semen Journal of Reproduction and Fertility $\mathbf{8 2} 717-725$

Holt WV, Abaigar T and Jabbour HN (1996a) Oestrus synchronization, semen preservation and artificial insemination in the mohor gazelle (Gazella dama mhorr) for the establishment of a genome resource bank programme Reproduction Fertility and Development 8 1215-1222

Holt WV, Bennett PM, Volobouev V and Watson PF (1996b) Genetic resource banks in wildlife conservation Journal of Zoology (London) 238 531-544

Howard JG, Wildt DE, Chakraborty PK and Bush M (1983) Reproductive traits including seasonal observations on semen quality and serum hormone concentrations in the dorcas gazelle Theriogenology $20221-234$

IUCN (1987) The IUCN Policy Statement on Captive Breeding. IUCN Publications Service, Cambridge

IUCN (1996) The Red List of Threatened Animals. IUCN Publications Service, Cambridge 
Jabbour HN, Argo CMcG, Brinklow BR, Loudon ASI and Hooton J (1993) Conception rates following intrauterine insemination of European (Dama dama dama) fallow deer does with fresh or frozen-thawed Mesopotamian (Dama dama mesopotamica) fallow deer spermatozoa Journal of Zoology (London) 230 379-384

Johnson L, Berndston WE and Pickett BW (1975) An improved method for evaluating acrosomes of bovine spermatozoa Journal of Animal Science $\mathbf{4 2}$ $951-954$

Kenagy GJ and Trombulak SC (1986) Size and function of mammalian testes in relation to body size Journal of Mammalogy $671-22$

M ller AP (1988) Ejaculate quality, testes size and sperm competition in primates Journal of Human Evolution 17 479-488

Monfort SL, Asher GW, Wildt DE, Wood TC, Schiewe MC, Williamson LR, Bush M and Rall WF (1993) Successful intrauterine insemination of Eld's deer (Cervus eldi thamin) with frozen-thawed spermatozoa Journal of Reproduction and Fertility 99 459-465

Morgenthal JC (1967) Notes on the spermatozoal morphology of some ungulates Journal of the South African Veterinary Medical Association 38 $271-273$

O'Brien SJ, Roelke ME, Newman A, Winkler CA, Meltzer D, Colly L, Everman JF, Bush M and Wildt DE (1985) Genetic basis for species vulnerability in the cheetah Science 227 1428-1434

Olmedo G, Escos J and Gomendio M (1985) Reproduction de Gazella cuvieri en captivité Mammalia 49 501-507

Pursel VG and Johnson LA (1974) Glutaraldehyde fixation of boar spermatozoa for acrosome evaluation Theriogenology 1 63-68

Pursel VG, Johnson LA and Ranpacek GB (1972) Acrosome morphology of boar spermatozoa incubated before cold shock Journal of Animal Science 34 $278-283$
Shams-Borhan G and Harrison RAP (1981) Production, characterization, and use of ionophore-induced, calcium-dependent acrosome reaction in ram spermatozoa Gamete Research 4 407-432

Talbot $\mathbf{P}$ and Chacon R (1981) A triple stain technique for evaluating normal acrosome reactions of human sperm Journal of Experimental Zoology 215 201-208

Tamuli MK and Watson PF (1994) Use of a simple staining technique to distinguish acrosomal changes in the live sperm sub-population Animal Reproduction Science 35 247-254

Watson PF (1975) Use of a Giemsa stain to detect changes in acrosomes of frozen ram spermatozoa Veterinary Record 97 12-15

Watson PF (1976) Electroejaculation, semen characteristics and semen preservation in the brindled gnu Journal of Reproduction and Fertility $\mathbf{4 7}$ 123-126

Wildt DE (1992) Genetic resource banks for conserving wildlife species: justification, examples and becoming organized on a global basis Animal Reproduction Science 28 247-257

Wildt DE, Bush M, Howard JG, O'Brien SJ, Meltzer D, van Dyk A, Ebedes $\mathrm{H}$ and Brand DJ (1983) Unique seminal quality in the South African cheetah and a comparative evaluation in the domestic cat Biology of Reproduction 29 1019-1025

Wildt DE, Bush M, Goodrowe KL, Packer C, Pusey AE, Brown JL, Joslin P and O'Brien SJ (1987) Reproductive and genetic consequences of founding isolated lion populations Nature 329 328-331

Woelders H (1991) Overview of in vitro methods for evaluation of semen quality. In Boar Semen Preservation II (Reproduction of Domestic Animals, Supplement 1) pp 145-164 Eds LA Johnson and D Rath. Paul Parey, Berlin

Zar JH (1984) Biostatistical Analysis 2nd Edn. Prentice-Hall, Inc., Englewood Cliffs, New Jersey 